\title{
brazilianpoliticalsciencereview
}

B OOK R E V I E W

\section{From National Dissension to International Negative Cycles*}

\author{
by Cristiana Dobre ${ }^{\dagger}$ \\ †Universidade de Brasília, Brasília, Distrito Federal, Brazil
}

(Niv-Solomon, Anat. Cooperation and Protracted Conflict in International Affairs: Cycles of Reciprocity. London: Palgrave Macmillan, 2016)

"Cooperation and Protracted Conflict in International Affairs" is a persuasive analysis of the application of the concept of reciprocity to the study of international relations. The interdisciplinarity of this book represents an added value to the literature on conflict resolution. The author, Anat Niv-Solomon, is an Associate Professor in political science at the College of Staten Island, New York, USA. She obtained her PhD degree from the University of Connecticut, completing a dissertation that she reworked to write this book. Solomon built a theoretical framework in her dissertation which she then applied in her first published book. Surprisingly, however, she does not mention or cite her dissertation in it. This is even more curious as both - dissertation and book - have the same title, but not the same content.

Her focus on decision making in foreign policy and on international negotiations led her to the study of resolution approaches in conflictual situations in international regimes. Solomon's publications from 2009 to the present mirror her interest in this field. Her involvement with the International Studies Association and with the Model Diplomacy Group from the Council on Foreign Relations of the United States demonstrates a real concern with mechanisms of negotiation among decision makers.

This book is one example of her analysis of possible outcomes stemming from critical situations. She stands out in comparison to most of her colleagues in this field of international relations research, by including and addressing the possibility of negative outcomes in critical juncture situations, as defined in comparative politics, rather than

(*) DOI: http://dx.doi.org/10.1590/1981-3821201800030010

This publication is registered under a CC-BY Licence. 
focusing only on the positive Tit-for-Tat (TFT) results. Solomon provides an overview of both options, and seeks to find an explanation for cooperative relations that end in negative cycles rather than in positive ones. For each case study, Solomon creates a framework table in which she identifies four variables in the critical juncture: symmetrical or asymmetrical power and issue saliency, negative, positive or neutral image and gains or losses in the domain of operation. Those indicators are examined in Chapter 02.

This "project", as she repeatedly names it, is based on the study of two real-world scenarios that she thoroughly investigated by applying the four selected variables to both case studies. The author engaged in a systematic qualitative research based on primary and secondary sources, such as "original government documents, official statements made by government representatives, newspaper articles from local and regional sources, past analysis of the cases, biographies and memoirs" (NIV-SOLOMON, 2016, p. 16). She used the International Crisis Behavior (ICB) database to limit the list of case possibilities that would clearly represent crisis situations. This online dataset provided her with information on variables describing the conflict cases, such as actors' situations, timeframes, conflict management or actions taken. She narrowed them down to the Mexico-Guatemala Fishing Rights crisis of 1958 and the Sino-Vietnam War that broke out in 1978. Two aspects that were essential in her selection were bilateralism and interstate dimensions, since for cases with more than two actors the applicability of the four variables would have been more limited, according to the author.

As mentioned above, this book provides international relations scholars and students with an alternative to the vast literature on positive TFT relations. Solomon repeatedly cites Robert Axelrode and his main work, "The Evolution of Cooperation", published in 1984, to call the readers' attention to her own contributions to the field. Indeed, positive reciprocity has been analyzed as an obvious outcome of cooperative relations over time. Solomon gives an opposite example by analyzing the Sino-Vietnam war in Chapter 03. These two countries used to have a history of positive relations based on solidarity and shared values, which the chapter describes extensively. Also, she evaluates the events from March to December 1978 which represented a critical juncture for both countries and catalyzed the war that started in February 1979. The conflict lasted only four weeks, but numerous casualties were reported. Besides, relations between the two countries never really recovered afterwards. Indeed, one of the arguments the author uses to emphasize the emergence of this critical juncture is the initiative by both countries in seeking the support of third parties, such as the United States for China, and the Soviet Union for Vietnam.

This specific point is interesting, since in the other case study, the Mexico-Guatemala fishing rights conflict described in Chapter 04, there were no external interventions and the outcome was just the opposite. The two countries managed to overcome their critical juncture de- 
spite the fact that the case was marked by power asymmetry. The prospect theory dimension highlights each country's national environment for domains of operation - that is, decisionmaking in situations of risk. In both countries the leaders were acting in the domains of gains, choosing a risk-averse attitude, due to public opinion support and therefore a high level of issue salience.

This book provides a valuable qualitative approach based on the examination of four analytical variables pertinent to the main issue, namely the negative cycles resulting from reciprocal relations (instead of the positive cycles). However, it also has some minor problems. Firstly, it lacks a brief analysis of the evolution over time of the two case studies. For example, it might have been informative to observe the Sino-Vietnam relationship over the years, since it never really overcame this critical juncture. This would have given a clearer view of the author's arguments to readers who specialize in international affairs, since these arguments can be critical to studies focused on short periods of time. Besides, Solomon briefly mentioned the possibility of a future study that would integrate multilateral relations, and not just bilateral ones. Since conflicts and cooperation are usually shared among more than two actors, something that is even more self-evident in global politics, bilateral relations seem to already incorporate, by their form and structure, more accessible solutions to "problems associated with fragmentation, competing values, and cultural diversity" (BLUM, 2008, p. 338).

Nevertheless, Solomon's book is essential not only to all scholars and students of international relations but also from other areas of study, like political science or development studies. Her focus on the contextualization of negative or positive cycles of reciprocity is innovative in the field of international relations, since she does not base her thesis on the assumptions that 01 . cooperative relationships necessarily lead to positive cycles of reciprocity, or that 02 . positive cycles of reciprocity lead to cooperative situations. She offers a method of analysis that is effective and that involves interdisciplinarity. Her last chapter briefly introduces two recent cases of critical juncture: the US-China conflict around the South China Sea and the USIran situation on the Iran nuclear deal. Solomon opens the door for new studies that would constitute an interesting follow-up to her present work.

Revised by Priscilla Kreitlon

\section{References}

AXELRODE, Robert (1984), The evolution of cooperation. New York: Basic Books Inc.. Publishers. 264 pp..

BLUM, Gabriella (2008), Bilateralism, multilateralism, and the architecture of international law. Harvard International Law Journal. Vol. 49, № 02, pp. 323-380. 